Please do not remove this page

RMIT

UNIVERSITY

\title{
Formation of lead lanthanum zirconate titanate films by heat treatments
}

Holland, Anthony; Kandasamy, Sasikaran; Fardin, Ernest; Mitchell, Arnan; McCulloch, Dougal

https://researchrepository.rmit.edu.au/esploro/outputs/9921859669401341/filesAndLinks?institution=61RMIT_INST\&\&index=null

Holland, A., Kandasamy, S., Fardin, E., Mitchell, A., \& McCulloch, D. (2005). Formation of lead lanthanum zirconate titanate films by heat treatments. Proceedings of the Conference on Optoelectronic and Microelectronic Materials and Devices, 109-112. https://doi.org/10.1109/COMMAD.2004.1577504

Published Version: https://doi.org/10.1109/COMMAD.2004.1577504

Repository homepage: https://researchrepository.rmit.edu.au

(C) 2005 IEEE

Downloaded On 2023/04/27 00:29:23 +1000

Please do not remove this page 


\title{
Formation of Lead Lanthanum Zirconate Titanate Films by Heat Treatments
}

\author{
Anthony S. Holland*, Sasikaran Kandasamy, Ernest Fardin, Arnan Mitchell, Dougal McCulloch, \\ School of Electrical and Computer Engineering, RMIT University, Melbourne, AUSTRALIA, \\ *Email: anthony.holland@rmit.edu.au
}

\begin{abstract}
Lead Lanthanum Zirconate Titanate (PLZT) also called Lanthanum doped PZT films were deposited by RF Magnetron sputtering. PLZT in the Perovskite phase is required to obtain a film with a large electro-optic effect. It can also be used as a ferroelectric and piezoelectric material. However films that have not been heat treated either during or after deposition are typically in the Pyrochlore phase. Perovskite PLZT films obtained by heating the substrate during sputtering showed little evidence of cracks in the films. Films sputtered without heating the substrate were not in the Perovskite phase and post deposition anneling was required to do so. Both furnace and Rapid Thermal Annealing were investigated but in both cases cracks formed in the films to various degrees. Such films are unsuitable for optical device fabrication. To determine the orientation of PLZT films X-ray diffraction (XRD) spectras were obtained and compared. Samples were prepared on Silicon substrates which had a thin film of $20 \mathrm{nmTi} / 100 \mathrm{nmPt}$ deposited by electron beam evaporation. Sputtering was done in an Argon atmosphere using a PLZT (9/65/35) target. Thicknesses of $1 \mu \mathrm{m}$ were obtained. Some samples were heated during sputtering up to a temperature of $650 \mathrm{C}$. Annealing temperatures were varied from 500 to $750^{\circ} \mathrm{C}$. The best results (determined by XRD) were obtained for RTA at $750{ }^{\circ} \mathrm{C}$ for 10 minutes in air. XRD spectra of before and after annealing show a significant increase in the Perovskite peaks. The patterning of these films to form optical waveguides by ion beam etching is also presented. The samples were patterned with photoresist masks and ion beam etched using argon at a gun voltage of $500 \mathrm{~V}$.
\end{abstract}

\section{Keywords: PLZT, XRD, Sputtering, Perovskite, annealing}

\section{INTRODUCTION}

The conventional material for making optical modulators is Lithium Niobate. PLZT has the advantage of a much higher electro-optic coefficient [1] and it can be deposited as a thin film e.g. on platinium (e.g. thin film on silicon) or directly onto sapphire substrates and integrated with silicon on sapphire devices [2]. However there are difficulties in obtaining good quality PLZT films with the desired orientation for optimum optical properties and free from microcracks [3]. The PLZT surface is very prone to cracking during post deposition heat treatments. The degree of cracking does vary depending on the heat treatment. The heat treatments investigated for obtaining the Perovskite phase PLZT were in-situ heating during sputtering, rapid thermal annealing (RTA) and furnace annealing.
The earliest reporting of sputtered PLZT is from the 1970's [1]. The PLZT phase required for optimum electro-optic effect is the perovskite phase. This is a phase that occurs in $\mathrm{ABO}_{3}$ type materials. The study of PLZT films typically uses XRD. There is no XRD reference file for PLZT in particular so the file that is used for XRD reference is that for PZT. The percentage of lanthanum is quite small and the crystal structure is PZT with lanthanum replacing some of the lead. We have used a $100 \mathrm{~mm}$ diameter $\mathrm{x} 1 / 8$ " PLZT target bonded to a $1 / 8$ " copper disc. RF magnetron sputtering was used for deposition. The target was clamped to the magnetron head so that the target is in contact with a $3 \mathrm{~mm}$ thick copper cooling plate which is part of the magnetron head and thus connected to the RF power supply and tuning circuit. The composition of this target is $\mathrm{Pb}_{(0.9)} \mathrm{La}(0.09) \mathrm{Zr}_{(0.75)} \mathrm{Ti}_{(0.3)}$. PLZT is a ceramic target and therefore can break if expansion due to heat is restricted. For ceramic targets the clamping issue can be more important than the heat sinking. Ceramic targets can be heated to thousands of degrees Celcius before degrading. If they are clamped and cannot expand then they may crack as heating occurs. For uniform and repeatable deposition the target temperature should be steady. In order to reduce the stress on the target and allow expansion graphite gaskets were used.

In order to obtain the perovskite phase of PLZT the film must be heated to $700 \mathrm{C}$ either during deposition or in a subsequent heat treatment, either furnace anneal or RTA. Furthermore the PLZT only gives the desired orientation on certain surfaces i.e. $\mathrm{Pt}, \mathrm{MgO}$ and Sapphire. In this study we report on sputtering PLZT films on Pt. Cracking of the deposited films by annealing is a major problem and therefore in-situ heating is preferred. Not all sputtering systems have substrate heaters that can operate in a suitably low pressure at $750 \mathrm{C}$ but results indicate that this is the best method for obtaining smooth Perovskite films. Good thermal contact between the sample and the heater is essential to ensure that the substrate is at the desired temperature. This is obtained by clamping the sample to the heater surface.

PLZT is difficult to pattern into optical devices using wet etching. Therefore ion beam etching has been investigated here on the films deposited to establish etching conditions. The smooth, as deposited films can be etched using this system to give smooth features e.g. ribs. 


\section{EXPERIMENTAL}

Three inch diameter (100) silicon wafers were cleaned and coated with $20 \mathrm{~nm}$ of titanium followed by $100 \mathrm{~nm}$ of platinium in an e-beam evporation system. Some samples were cleaved into $1 \mathrm{~cm} \times 1 \mathrm{~cm}$ pieces for testing sputter deposition of PLZT. The sputtering conditions are given in Table I. The sputtering system used a turbomolecular pump. The substrate heater was an electrically resistive heater type. For some samples the substrates were heated to various temperatures (up to 650C). Samples that were not heated using the substrate heater were annealed after deposition of the PLZT. The annealing conditions were RTA for 10 minutes at temperatures of $600 \mathrm{C}$ to $750 \mathrm{C}$ and a ramp rate of approximately $20 \mathrm{C} / \mathrm{second}$. Furnace annealing was at $600 \mathrm{C}$ for 1 hour. Film thicknesses of approximately $1 \mu \mathrm{m}$ were obtained. X-ray Diffraction (XRD) was used to determine the crystal structure of the films. For Ion Beam Etching (IBE) the samples were patterned with AZ1512 photoresist. A $5 \mathrm{~cm}$ diameter Kaufmann ion beam gun was used. The vacuum system consisted of a cryopump. The etching conditions are given in Table II. In this system the samples were adhered to the sample table using a thermal paste

(a)

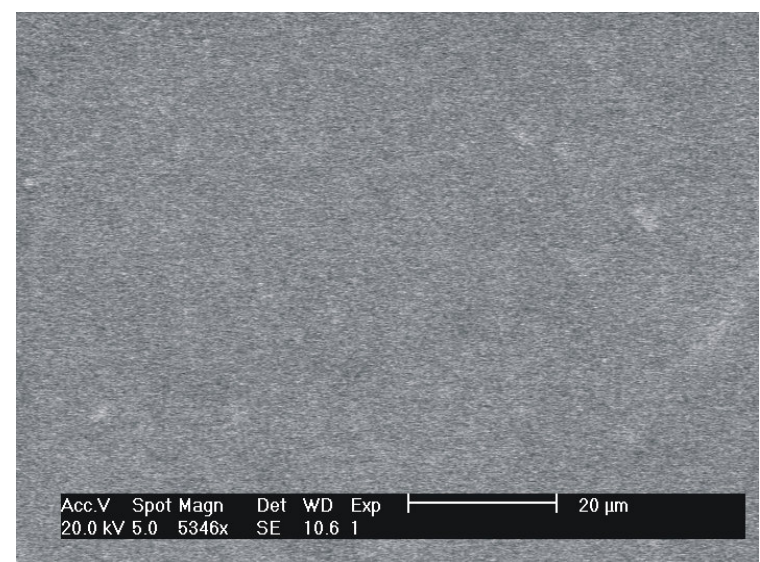

(b)

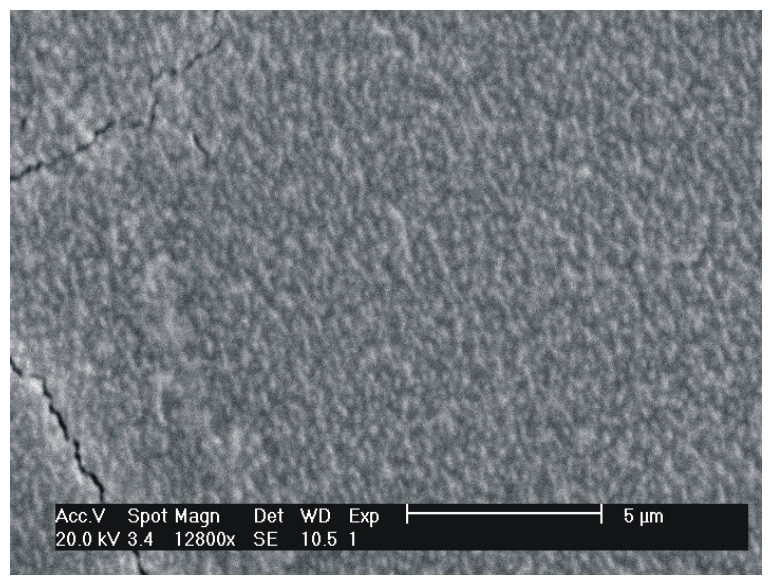

Figure 1. SEM micrographs of PLZT deposited without substrate heating, (a) as deposited (b), (c) post-deposition RTA at 750C and (d) post deposition furnace anneal at $600 \mathrm{C}$ suitable for vacuum. This is essential to ensure continuous cooling of the sample so as to prevent the photoresist layer from being damaged due to heating of the sample by the bombarding ions.

TABLE I. RF MAGNETRON SPUTTERING CONDITIONS USED FOR PLZT

\begin{tabular}{cc}
\hline \hline RF power & 80 Watts \\
Gas & Argon \\
Run pressure & $5 \times 10^{-3}$ Torr \\
$\begin{array}{c}\text { Target to substrate } \\
\text { distance }\end{array}$ & $6 \mathrm{~cm}$ \\
\hline
\end{tabular}

TABLE II. IBE CONDITIONS FOR PLZT

\begin{tabular}{cc}
\hline Gun voltage & $500 \mathrm{~V}$ \\
Gas & Argon \\
Run pressure & $2 \times 10^{-4}$ Torr \\
Gun angle (off normal) & $22.5^{\circ}$
\end{tabular}

(c)

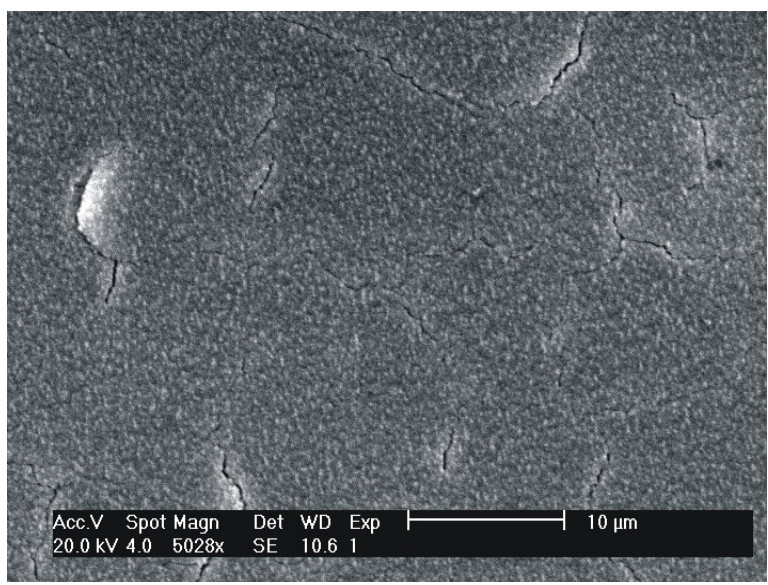

(d)

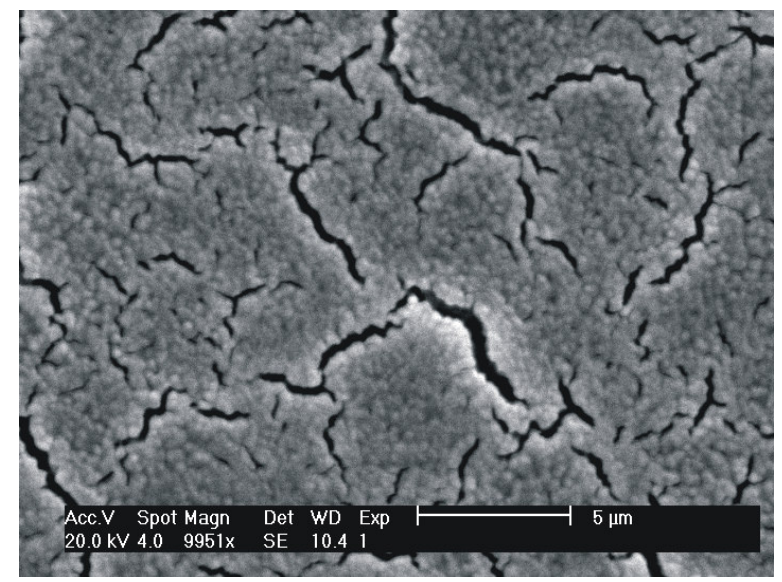


(a)

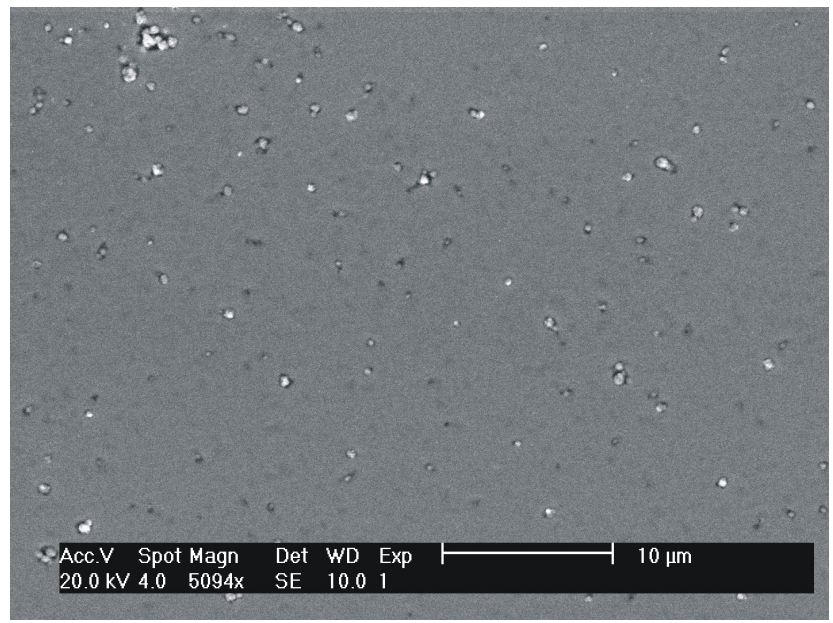

(b)

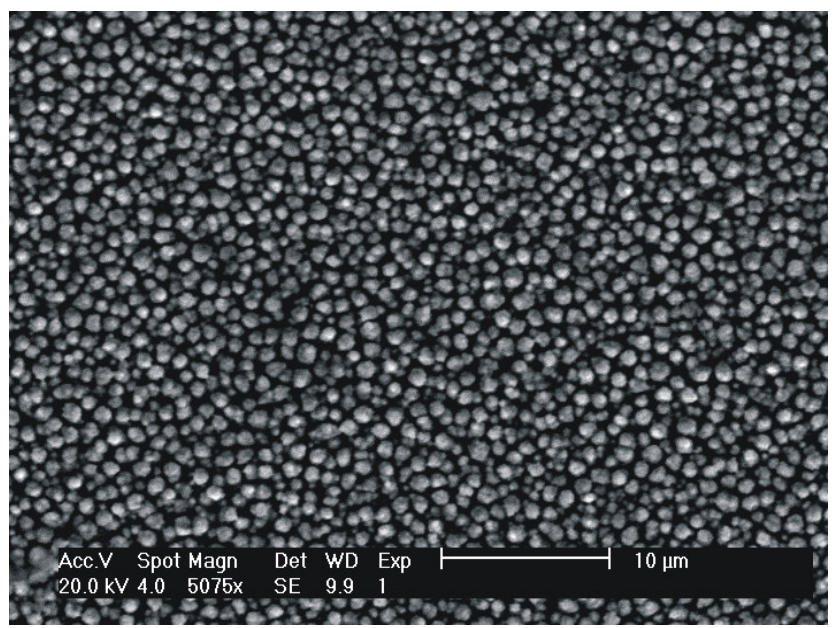

Figure 2. SEM micrographs of PLZT deposited with substrate heating, (a) $550 \mathrm{C}$ (b) $650 \mathrm{C}$.

\section{RESULTS AND DISCUSSION}

It was noted that the position of the sample in the sputtering process affected the appearance of the annealed film and the XRD spectra obtained. 3" silicon wafers were sputtered and the poorer quality films were obtained nearer the wafer edges. Poor quality was evident by cracking and peeling of the films. Cracking in the films was evident in most samples. Figure 1 shows SEM micrographs of PLZT films that were sputtered without in-situ heating. Figure 1(a) is the as deposited film surface and shows that the films are smooth. However XRD analysis shows that the films are not in the Perovskite phase. Figure 1(b) and (c) are of films heated by RTA at 750C. The films are in the Perovskite phase but microcracks have developed due to the post deposition heating. The area shown in the micrograph is one of the better areas of the sample. Figure 1(d) shows the surface of a sample that was furnace annealed at 600C. Samples annealed in this way had a much
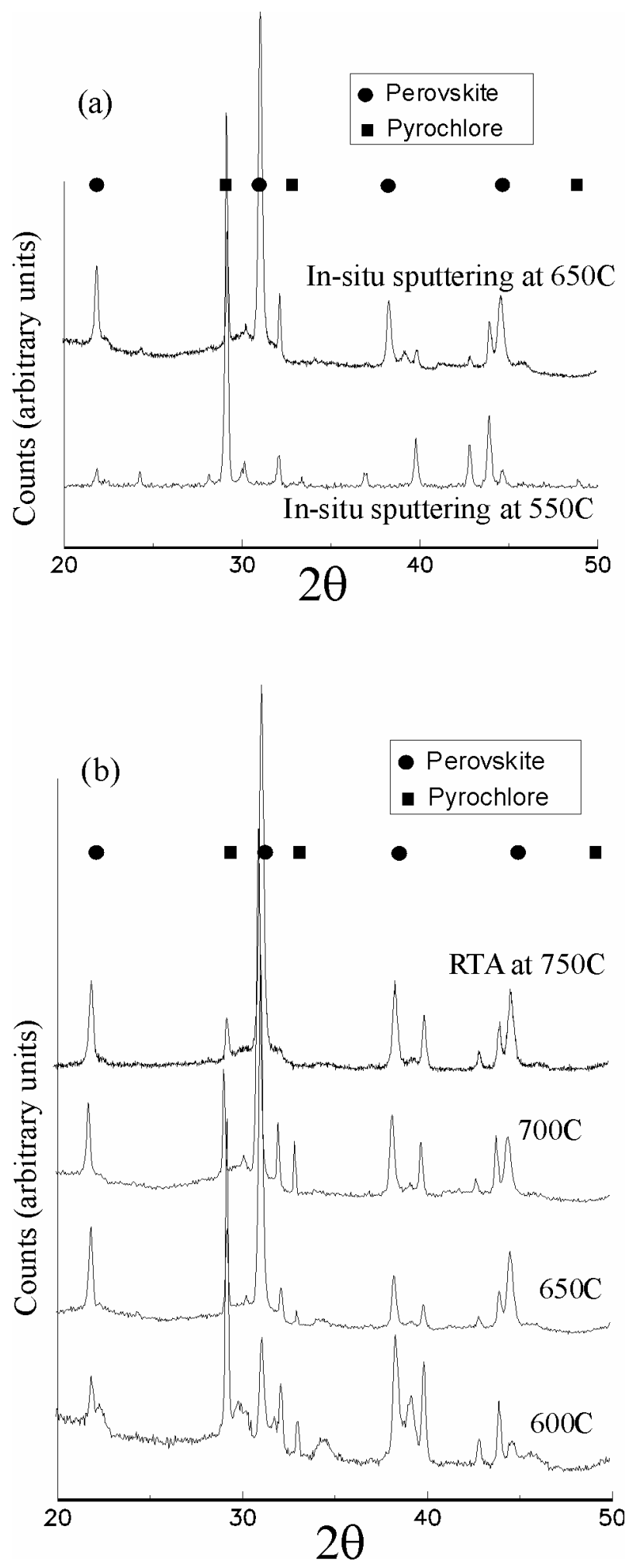

Figure 3. XRD spectras for (a) films heated during PLZT sputter deposition (b) films sputtered without heating and post deposition annealed. No Perovskite peaks were observed for the furnace annealed samples. 
higher density of cracks and did not show the Perovskite phase in XRD spectras. At higher temperatures the cracking was more and the films appeared to be peeling off the substrates as tiny flakes. The XRD spectras of RTA films is shown in Figure 3(b). There is a distinct increase in the Perovskite phase with increasing temperature. Shorter RTA times did not appear to reduce the cracking and had relatively less intensity XRD peaks corresponding to Perovskite phase PLZT. However there is some variation in the cracking behaviour of the films. Some areas of similarly prepared and processed films had distinctly different density of cracking after RTA processing. This may have been the results of some non-uniformity in the RF magnetron sputtering process. Larger samples showed increased cracking near the sample edges.

Figure 2 shows that the Perovskite films obtained by heating the substrate during deposition gives more uniform films. The highest temperature used was $650 \mathrm{C}$ and improvements may be possible if our heater was capable of higher temperatures. The texture of the surfaces shown in Figure 2 (a) and (b) are quite different and it appears for Fig 2(a) that the crystallites, very evident in Fig 2(b), are beginning to form. The corresponding XRD spectras shown in Figure 3(a) also suggest this.

PLZT films were etched using the ion beam etching condition given in table II. An etch depth of approximately $0.5 \mu \mathrm{m}$ was obtained in 20 minutes for films which showed a variety of Perovskite phase content.

\section{CONCLUSIONS AND FUTURE WORK}

In this study the best Perovskite PLZT films were obtained by in-situ heating during sputtering deposition. For substrates that were not heated during PLZT deposition post deposition by furnace annealing was not suitable for forming the Perovskite phase but post deposition annealing by RTA did significantly improve the Perovskite phase content of the films. The problem with post deposition annealing was the appearance of micro-cracking of the films. This was much less in the RTA films with a variety of cracking densities occuring. The in-situ heating of the substrates can be improved to give a substrate temperature of 700 to $750 \mathrm{C}$ which may further improve the Perovskite PLZT content of the films and possibly remove any non-Perovskite crystallites. Smooth etched features are necessary for forming waveguides and Electro-optical devices. Ion beam etching is a suitable process for etching such patterns on PLZT films. An etch rate of $0.5 \mu \mathrm{m}$ in 20 minutes has been obtained in this study.

\section{REFERENCES}

[1] G. H. Haertling and C. E. Land, "Hot-Pressed $(\mathrm{Pb}, \mathrm{La})(\mathrm{Zr}, \mathrm{Ti}) \mathrm{O}_{3}$ Ferroelectric Ceramics for Electrooptic Applications", J. Am. Ceram. Soc., Vol. 54, pp. 1-11, 1971

[2] S. Krishnakumar, V. H. Ozguz, C. Fan, S. C., Esener and S. H. Lee, "Deposition and characterization of thin ferroelectric lead lanthanum zirconate titanate (PLZT) films on sapphire for spatial light modulators applications", IEEE Trans. on Ultrasonics Ferroelectrics and Frequency Control, Vol. 38, No.6, pp. 585589, 1991.

[3] B.Jaber, D. Remiens, E. Cattan, B. Thierry, "Optimisation of the deposition and annealing parameters of paraelectric PLZT $(28 / 0 / 100)$ thin films grown by RF magnetron sputtering", Sensors and Actuators A51, pp. 1-4, 1995. 